\title{
ECRG-4 expression in normal and neoplastic choroid plexus
}

\author{
John E Donahue ${ }^{1 *}$, Miles C Miller ${ }^{1}$, Virginia Breese ${ }^{1}$, Sonia Podvin², Brian Eliceiri², Cynthia L Jackson', \\ Conrad E Johanson ${ }^{3}$, Edward G Stopa ${ }^{1}$, Ana Maria Gonzalez ${ }^{4}$, Andrew Baird ${ }^{2}$ \\ From 54th Annual Meeting of the Society for Research into Hydrocephalus and Spina Bifida \\ Vancouver, Canada. 7-10 July 2010
}

\section{Background}

The choroid plexus is a major site of gene expression of esophageal cancer-related gene (ECRG)-4 during development, suggesting that its gene product may be involved in cerebrospinal fluid (CSF) homeostasis. Yet, ECRG-4 is also a novel candidate tumor suppressor gene whose expression is downregulated and is inversely associated with a worse prognosis in several different cancers. Reduced expression of ECRG-4 has been demonstrated in most tumors, including colorectal carcinoma and malignant glioma, to be mediated by hypermethylation of its promoter.

\section{Materials and methods}

In this study, samples of normal human choroid plexus (both fetal and adult) and choroid plexus neoplasms (WHO grade I papilloma, grade II atypical papilloma, and grade III carcinoma) were stained with antibodies that we generated to augurin, the gene product of ECRG4. DNA was then extracted from the tissue, treated with bisulfite, and subjected to PCR using a 217-base pair region encompassing the ECRG-4 promotor to detect methylation.

\section{Results}

Both fetal and adult human choroid plexus cells demonstrated a robust positive immunostaining at the apical surface that is consistent with our prior results in human, rat, and mouse brains. In contrast, there was a near-complete absence of immunostaining in all of the choroid plexus neoplasms examined. The choroid plexus carcinoma demonstrated significant methylation of the ECRG-4 promotor region.

\section{Conclusions}

Taken together, these data suggest that ECRG-4 is downregulated in neoplasms of the choroid plexus just as has been observed in other central nervous system (CNS) and non-CNS cancers. This is likely due to hypermethylation of the ECRG-4 promotor, as shown in the choroid plexus carcinoma. Further analysis is underway to determine the (1) physiologic and (2) pathophysiologic consequences of ECRG-4 over- and under- expression in the choroid plexus on CSF formation, function, and composition.

\section{Author details}

'Dept. of Pathology, Rhode Island Hospital/Alpert Medical School, 593 Eddy St (APC 12115), Providence, Rl 02903, USA. ${ }^{2}$ Dept. of Surgery, UCSD Medical Center, 212 Dickinson St, CTFB310 MS 8296, San Diego, CA 92103, USA.

${ }^{3}$ Dept. of Neurosurgery, Rhode Island Hospital/Alpert Medical School, 593 Eddy St, Providence, RI 02903, USA. ${ }^{4}$ Neuropharmacology and Neurobiology Section, School of Clinical and Experimental Medicine, College of Medical and Dental Sciences, Institute of Biomedical Research (West), University of Birmingham, Edgbaston, Birmingham B15 2TT, UK.

Published: 15 December 2010

doi:10.1186/1743-8454-7-S1-S32

Cite this article as: Donahue et al: ECRG-4 expression in normal and neoplastic choroid plexus. Cerebrospinal Fluid Research 2010 7(Suppl 1):S32.

\footnotetext{
* Correspondence: JDonahue3@Lifespan.org

'Dept. of Pathology, Rhode Island Hospital/Alpert Medical School, 593 Eddy St (APC 12115), Providence, RI 02903, USA

Full list of author information is available at the end of the article
} 